\title{
Benchmarks for energy access: policy vagueness and incoherence as barriers to sustainable electrification of the global south
}

\author{
Chukwuka G. Monyei, Lukumon O. Oyedele*, Olugbenga O. Akinade, Anuoluwapo O. Ajayi \\ and Xiaojun J. Luo
}

Big Data Enterprise and Artificial Intelligence Laboratory (Big-DEAL), University of the West of England (UWE), Frenchay Campus, Bristol, United Kingdom

*Corresponding author: L.Oyedele@uwe.ac.uk

\begin{abstract}
The unavailability of tangible policy benchmarks continues to mitigate against sustainable electrification in the global south. Furthermore, incoherent policy benchmarks as to what should constitute clean energy allow for varying interpretations and divergent options in electrifying households across the global south. The multiplicity of policies to deepen access to improved energy services in the global south notwithstanding, 'success' is not in sight until definite and uniform benchmarks guide the roll-out of electrification schemes.
\end{abstract}

Keywords: - incoherent policies; electrification policy benchmarks; global south.

\subsection{Introduction}

Policies such as the clean development mechanism (CDM), the Paris Climate Change Agreement and goal 7 of the sustainable development goals (SDG 7) have arisen out of a global need to: (1) arrest climate change and (2) combat poverty especially in the global south through sustainable development [1]. As of August 2018, UNFCCC in [2] reports that CDM had incentivised the registration of over 8,100 climate projects in 111 developing countries, including investments in excess of USD 300 billion and $\mathrm{CO}_{2}$ reduction or avoidance exceeding 2 billion tonnes. Similarly, UNFCCC in [3] offers that the Paris Climate Change Agreement attempts at limiting global warming to $1.5^{\circ} \mathrm{C}$ to $2^{\circ} \mathrm{C}$ above pre-industrial levels. Also, SDG 7 as outlined in [4] aims to "Ensure access to affordable, reliable, sustainable and modern energy for all" and here-in we argue lies the problem.

The significant investments notwithstanding, policy vagueness ${ }^{1}$ surrounding non-availability of key indices like what should constitute sufficient electricity access and electricity mobility including uniform and definite benchmarks mean that over 1 billion persons still live without electricity worldwide [5]. Furthermore, it can be argued that many so-called off-grid "electrified" households in the global south can be classified as un-electrified considering the inability of their electrification system to offer them any utility [6].

\footnotetext{
${ }^{1}$ For the purpose of explication, we define policy vagueness (which is unfolded in the course of this perspective) to be the absence of uniform benchmarks and minimum targets including use of vague (bogus) terminologies that allow for divergent interpretations and variegated applications. Such applications can result in marginalisation and injustice based on differing quality of service.
} 
Acknowledging efforts at rephrasing energy access as a justice issue [e.g., as discussed in [7, 8], we outline three key policy aspects that must be addressed timeously before electrification policies can elicit considerable positive changes from the global south. The urgency for an overhaul of electrification policies for off-grid communities in the global south we further offer is necessary to avoid global emissions from the global south eroding carbon emissions reduction efforts from the global north. These policy aspects include: (i) creating uniform benchmarks for what should constitute sufficient electricity access, (ii) defining a minimum extent that electrification schemes should provide for electricity mobility and, (iii) localising global decarbonisation pathways for off-grid communities in the global south.

\subsection{Creating uniform benchmarks for what should constitute electricity access.}

The inability to define what should constitute electricity access creates room for divergent interpretations. This we argue can precipitate instances of injustice. Furthermore, there is the possibility for such lacuna to be exploited by the global north especially when off-shoring climate mitigation schemes to the global south [9].

In South Africa for instance, the disparity in the quantity of electricity that indigent households can access under the free basic electrification (FBE) policy and the Non-Grid Electrification Policy Guidelines promotes injustice and rural marginalisation [6]. Without uniformity and benchmarks governing such policy schemes, off-grid indigent households are faced with the possibility of exacerbated energy poverty due to increasing energy burdens. This is as a result of increased energy expenses from financing the renewable energy-based electrification service (which offers no utility most times due to weather unavailability and low battery storage) and also sourcing for alternative fuels to meet household needs of cooking, illumination, indoor heating and water heating.

With the consideration of benchmarks on electricity access in off-grid electrification policy roll-outs, a minimum standard of electricity in terms of quantity and quality is guaranteed. The potential benefits of such consideration include improvement in the quality of life of households, elimination of rural marginalisation, reduction in the energy burden of households and significant reduction in carbon emissions [6]. Table 1 presents a comprehensive analysis of the disparities across South Africa's trilateral energisation ${ }^{2}$ approach (TEA) benchmarked with key indices from the Energy Justice Framework [7]. TEA we define to be a suite of energisation schemes - FBE, Non-Grid Electrification Policy Guidelines and the Free Basic Alternative Energy Policy through which households across South Africa are energised.

\subsection{Defining a minimum extent that electrification schemes should provide for electricity mobility.}

Electricity mobility (see Figure 1 ) is defined as the ability of households to increase their electricity consumption based on either an increase in the ownership of owned electrical appliances or extended usage of already owned electrical appliances [10]. Differing from the popular energy ladder, electricity mobility assesses the ability of the utility (mini-grid, micro-

\footnotetext{
${ }^{2}$ The use of the term energisation encompasses all forms of energy (not necessarily electricity alone) utilised by households in meeting their energy needs.
} 
grid, SHS) to guarantee the possibility of electricity consumption expansion for households up to an extent.

Acknowledging that the potential for an electrification scheme to guarantee electricity mobility is guided by the ease of expanding the utility's capacity and the associated costs of expansion, Monyei et al [6] argue that individual SHS for indigent off-grid households may not be a viable option [see Table 1 for a more detailed analysis]. This is because of the limited financial capacity of such households to offset incurred costs. Defining minimum limits that microgrids and mini-grids should guarantee electricity mobility for connected households is capable of spurring economic development since households can expand their ownership of electrical appliances to include devices that can be used for small scale businesses (see [11, 12] for the impact of increased duration of electricity access on the economic development and satisfaction level of households in India). We further offer that arguments highlighting the low electricity demand capacity of off-grid communities and suggesting limited capacity roll-out schemes are untenable owing to the ability of the conventional grid to guarantee indigent households' "infinite" electricity as long as they can pay.

1.3 Localising global decarbonisation pathways for off-grid communities in the global south. Globally, decarbonisation of the electricity sector follows two routes (shown in Figure 2) - the sequential displacement and hybridisation decarbonisation routes [13]. While the sequential displacement decarbonisation route (see Figure $2 a$ ) involves the gradual displacement of a member of the dominant regime (for instance, nuclear) with a disruptor (natural gas, VRE), the hybridisation decarbonisation route (see Figure $2 \mathrm{~b}$ ) involves an interplay between a regime member (for instance, coal) and a niche innovation (biomass, CCS). The implication of these decarbonisation routes is an inherent realisation that a $100 \%$ decarbonisation of the electricity grid cannot be achieved immediately.

It is thus unjust and unrealistic for the global north and international finance corporations (IFCs) to insist on financing policies and projects for off-grid communities in the global south that are $100 \%$ renewable based. We make this argument based on findings from [6] where it was sufficiently shown that incorporating diesel generators for 'firming' a central microgrid scheme that utilised solar PV, battery storage and a smart load manager achieved over $70 \%$ reduction in $\mathrm{CO}_{2}$ emissions compared to a $100 \%$ based individual household solar PV system (with battery storage).

Owing to the potential for solar irradiance stochasticity and intermittency to disrupt electricity supply, and unnecessarily over-size installations, we argue that utilising the hybrid generation scheme (solar PV and diesel generator) is capable of permanently displacing households' usage of coal for cooking, water heating and clothes ironing. While unconventional, this sequential displacement of coal with a hybridised system (at the off-grid community level) is similar to the growing incorporation of natural gas power plants as an intermediate replacement for coal power plants in the energy mix of countries. Similar to the use of conventional power sources like natural gas and nuclear to firm renewable energy sources at large-scale, the incorporation of diesel generators in the proposed hybrid generation scheme in [6] 'firms' the renewable component by guaranteeing availability of supply that is also sufficient and stable. 


\subsection{Conclusion}

Our attempt throughout this paper has not been to condemn existing off-grid electrification policies for the global south but rather to: (1) highlight their inadequacies, and (2) draw attention to the commonly overlooked issues of non-uniformity and incoherence in benchmarks for guaranteeing availability, sufficiency and mobility in electrification projects. By failing to provide such tangible benchmark values, IFCs and national governments in the global south are allowed free reign to adopt varied metrics in the roll-out of electrification projects. This disparity in standards we argue is capable of precipitating instances of injustice.

Furthermore, considering the possibility for such projects to offer no utility to connected households and their inability to displace the use of dominant fuel sources like coal and firewood, there is the likelihood for the global south to erode emissions reduction efforts of the global north. This is because the goal of limiting climate change is based on a global averaging of national efforts. We also offer that the targets of SDG 7 might be unattainable owing to complications arising over what should constitute sustainable electrification in the global south. By excluding fossil fuels even for 'firming' purposes, so-called electrification projects like SHS and renewable energy-based microgrids run the risk of failure owing to intermittent weather conditions.

Lastly, we offer that arguments in support of oversizing renewable energy systems to counteract weather issues and obviate the need for fossil fuel-based generation schemes for 'firming' purposes are unrealistic since such measures come at a cost that can make them economically unviable. We conclude that policy makers and national governments especially in the global south must adopt a quantitative-based policy framework for electrification schemes. Such framework must provide tangible benchmarks that are uniformly and internationally agreed over what should constitute minimum and sufficient electricity access including the extent for electricity mobility. The incorporation of allowances for the minimal exploitation of fossil fuels strictly for 'firming' purposes and away from households (e.g., as applied in [6]) we conclude can help eliminate households direct use of other fossil fuel sources like coal and firewood and reduce instances of chronic obstructive pulmonary disease (COPD).

\section{Acknowledgement}

The authors would like to acknowledge and express their sincere gratitude to The Department for Business, Energy \& Industrial Strategy (DBEIS) through grant project number TEIF-1017025. Opinions expressed and conclusions arrived at are those of the authors and are not to be attributed to the sponsor. 


\section{References}

[1] Jeayoon Kim, Kwangwoo Park (2018), "Effect of the Clean Development Mechanism on the deployment of renewable energy: Less developed vs. well-developed financial markets". Energy Economics, 75, 1-13, ISSN 0140-9883

[2] UNFCCC (2018), Clean Development Mechanism Passes New Milestone. https://unfccc.int/news/clean-development-mechanism-passes-new-milestone

[3] UNFCCC (2018), The Paris Agreement. https://unfccc.int/process-and-meetings/the-parisagreement/the-paris-agreement

[4] https://unstats.un.org/sdgs/report/2016/goal-07/

[5] The World Bank (2018), The Race for Universal Energy Access Speeds Up. https://www.worldbank.org/en/news/feature/2018/07/10/the-race-for-universal-energy-

access-speeds-up

[6] C.G. Monyei, A.O. Adewumi, and K.E.H. Jenkins (2018) "Energy (in)justice in off-grid rural electrification policy: South Africa in focus". Energy Research and Social Science, 44, 152-171, ISSN 2214-6296

[7] B.K. Sovacool and M.H. Dworkin (2015), "Energy justice: Conceptual insights and practical applications". Applied Energy, 142, 435-444, ISSN 0306-2619

[8] K. Jenkins, D. McCauley, R. Heffron, H. Stephan, R. Rehner (2016), "Energy justice: A conceptual review". Energy Research \& Social Science, 11, 2016, 174-182, ISSN 2214-6296

[9] C.G. Monyei, K. Jenkins, V. Serestina, A.O. Adewumi (2018), "Examining energy sufficiency and energy mobility in the global south through the energy justice framework". Energy Policy, $119,68-76$, ISSN 0301-4215

[10] C.G. Monyei, L.O. Oyedele, O.O. Akinade, A.O. Ajayi, A.E. Ezugwu, K.O. Akpeji, S. Viriri, A.O. Adewumi, D. Akinyele, O.M. Babatunde, M.O. Obolo, J.C. Onunwor (2018), "An incomereflective scalable energy level transition system for low/middle income households". Sustainable Cities and Society, ISSN 2210-6707

[11] Aklin, M., Cheng, C.Y., Urpelainen, J., Ganesan, K. and Jain, A., 2016. Factors affecting household satisfaction with electricity supply in rural India. Nature Energy, 1(11), p.16170.

[12] Aklin, M., Bayer, P., Harish, S.P. and Urpelainen, J., 2017. Does basic energy access generate socioeconomic benefits? A field experiment with off-grid solar power in India. Science advances, 3(5), p.e1602153.

[13] Chukwuka G. Monyei, Benjamin K. Sovacool, Marilyn A. Brown, Kirsten E. H. Jenkins, Serestina Viriri and Yufei Li (2019), "Justice, Poverty, and electricity decarbonization." The Electricity Journal, 32(1), 47-51, ISSN 1040-6190. 
[14] Monyei, C. G., and Adewumi, A. O. (2017) "Demand Side Management potentials for mitigating energy poverty in South Africa". In: Energy Policy 111.Supplement C, pp. 298-311. ISSN: 0301-4215

[15] Monyei, C.G., Jenkins, K., Viriri, S. and Adewumi, A. O. (2018c) "Policy discussion for sustainable integrated electricity expansion in South Africa". Energy Policy, 120. pp. 132-143. ISSN: 0301-4215

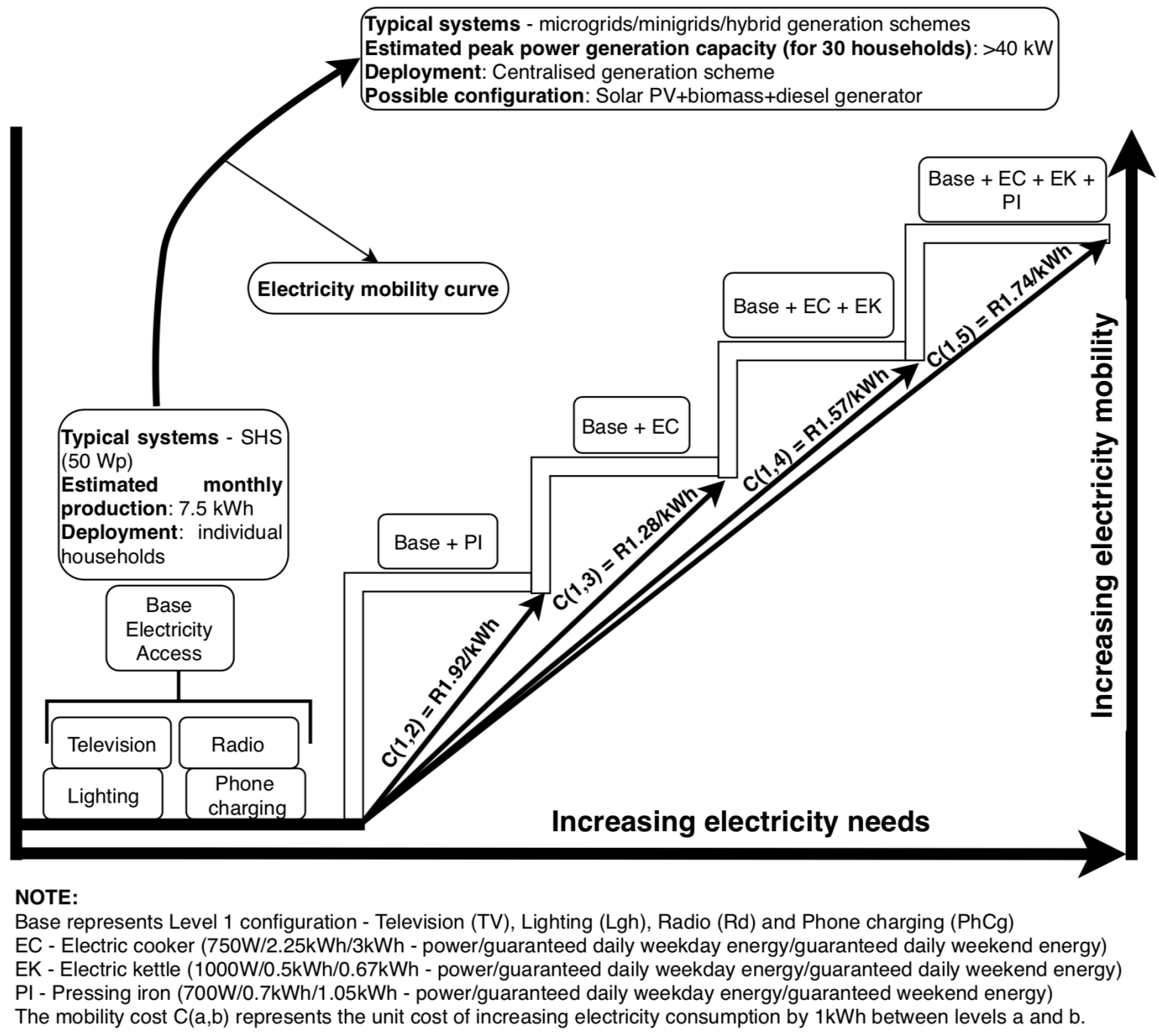

Figure 1: The electricity mobility ladder

Further discussion: Figure 1 presents the electricity mobility ladder for off-grid households connected to a central hybrid system (solar PV and diesel generator) [(see [6] for detailed methodology and results)]. The mobility of houses from one level to another involves unit incremental mobility costs depending on the supply configuration chosen. 


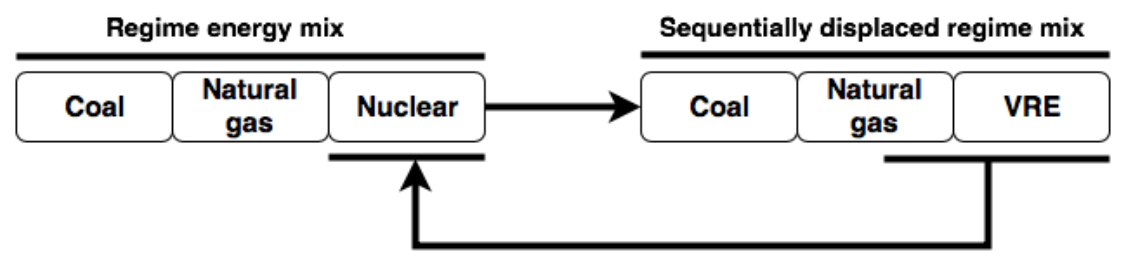

(a)

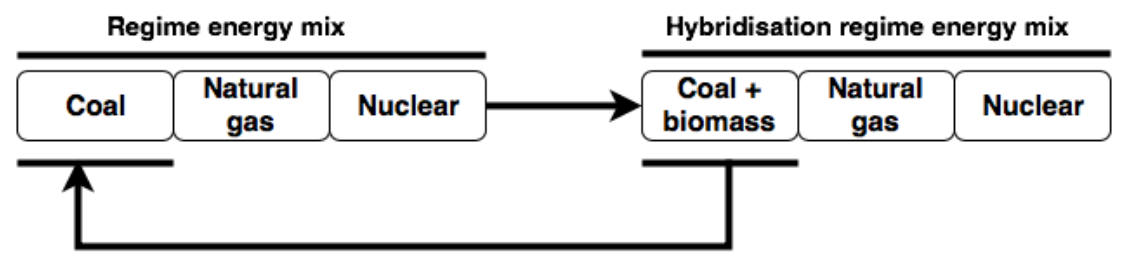

(b)

Figure 2: Decarbonisation pathways for (a) sequential displacement and (b) hybridisation strategy

Table 1: Exhaustive assessment of South Africa's Trilateral Energisation Approach (TEA)

\begin{tabular}{|c|c|c|c|}
\hline & \multicolumn{3}{|c|}{ Trilateral Energisation Approach (TEA) of South Africa } \\
\hline & Grid-connected households & Off-grid households 1 & Off-grid households 2 \\
\hline Economic status & Vulnerable, poor & Vulnerable, poor & Vulnerable, poor \\
\hline Implication & $50 \mathrm{kWh} /$ month & $7.5 \mathrm{kWh} /$ month & Subsidised fuels \\
\hline \multicolumn{4}{|c|}{ Exhaustive assessment of TEA } \\
\hline Sufficientarianism & $\mathrm{V}^{*}$ & $\mathrm{X}^{1}$ & $x^{2}$ \\
\hline Availability & $\mathrm{V}^{* *}$ & $X^{3}$ & $x^{4}$ \\
\hline Libertarianism & $\mathrm{V}^{* * *}$ & $x^{5}$ & $\mathrm{~V}^{6}$ \\
\hline Utilitarianism & $\mathrm{V}^{* * * *}$ & $X^{7}$ & $\mathrm{X}^{8}$ \\
\hline Egalitarianism & $\mathrm{V}^{* \wedge}$ & $X^{9}$ & $\mathrm{X}^{10}$ \\
\hline Ease of mobility & $\mathrm{V}^{* * \wedge}$ & $\mathrm{X}^{11}$ & $\mathrm{~V}^{12}$ \\
\hline $\begin{array}{c}\text { Potential to } \\
\text { mitigate emissions }\end{array}$ & $\mathrm{V}^{* * * \wedge}$ & $x^{13}$ & $X^{14}$ \\
\hline
\end{tabular}

Off-grid households 1 refer to off-grid households that are supplied with solar home system (SHS); Off-grid households 2 refer to off-grid households supplied with subsidised fuels to meet their energy needs (cooking, heating, boiling water and lighting); $\mathrm{V}$ - implies that the TEA component can meet (extent is subsequently defined) with selected qualities, $X$ - implies that TEA component cannot be meet with selected qualities; vulnerable and poor households are households whose monthly income is less than R992/month.

* - Highlighted by Monyei et al [9] to meet the sufficientarianism principle by Sovacool and Dworkin [7]; ** - Deemed to meet the availability principle considering Eskom's ability to overcome issues of load shedding (post 2008) and guarantee constant electricity supply. Scheduled outages are assumed to be occasioned by planned maintenance and do not count as affecting availability; *** - Grid electricity offers households the freedom to utilise their subsidised electricity (within the month) when and how they choose without any restrictions (subject to their connection current ratings) on possible electrical appliances that can be utilised; **** - Households derive maximum utility from supplied electricity since it is clean, free, readily available and places no restriction (up to connection current ratings) on electrical appliances that can be used or when electricity should be used; $* \boldsymbol{\wedge}$ - The electricity access that is provided 'privileges' the poor and vulnerable households connected to the grid ensuring they enjoy same quality of electricity as other grid-connected households (there is no discrimination between grid connected 
households on type or quality of electricity to receive based on economic status); ${ }^{* * \wedge}$ - ease of mobility is guaranteed considering the incorporation of generator expansion planning (GEP) in expanding supply capacity of the conventional grid and the availability of reserve margins to allow for sudden increase in electricity consumption (up to an extent) without compromising on grid security; ${ }^{* * * \wedge}$ - opportunities abound for mitigating emissions. First, households could adopt the usage of energy efficient electrical appliances to cut down on electricity usage while the utility could exploit the integration of renewable energy sources into the energy mix which also provides an avenue for reducing emissions. Demand side management (DSM) could also play a role in assisting the utility fully integrate renewable energy projects (REPs). DSM potential for South Africa (for selected household appliances) has been investigated by Monyei and Adewumi [14] while a framework for integrating REPs with the grid and incorporating DSM has been further investigated for South Africa by Monyei et al [15].

${ }^{1}$ - for individual households, SHS has been methodologically assessed by Monyei et al [6] and shown not to meet with the requirements of sufficientarianism; ${ }^{3}$ - in reviewing SHS especially for individual households, Monyei et al [6] offer that the intermittency of solar irradiance negatively affects the availability of power from the SHS; ${ }^{5}$ - in an exhaustive assessment of SHS deployment across South Africa, Monyei et al [6] provide compelling experimental evidence to show that SHS do not met with libertarianism requirements since household users do not have liberty in determining when to use electricity owing to its (SHS) potential to be unavailable when needed (see preceding point); ${ }^{7}$ - the Duration-Comfort plot in Monyei et al [6] shows that households do not derive any utility from owned SHS due to the negative impact of weather intermittency on SHS output; ${ }^{9}$ - again, from Monyei et al [6], weather does affect SHS performance in unequal measures across South Africa which is further compounded by the inability of the policy guidelines to cater for varying weather effect. Furthermore, considering the disparity between gridconnected poor households and off-grid poor households in terms of quality of electricity provided, the SHS scheme does not meet with the expectations of egalitarianism; ${ }^{11}$ - shown not to guarantee mobility by Monyei et al [6] due to the unaffordable cost (for the poor off-grid households) of expanding SHS system (panel, batteries and charge controller) to cater for additional electrical loads; ${ }^{13}$ - shown by Monyei et al [6] to increase emissions due to its inability in most cases to displace household coal usage.

${ }^{2}-a b$ initio, rations of subsidised fuels which are distributed to houses are deemed limited which contradicts the expectations of sufficientarianism; ${ }^{4}$ - considering the possible dependence of the state on imports to offset needs under this scheme, external shocks occasioned by politics, conflicts, economic restrictions and embargoes could adversely affect the cost and ultimately the availability of these fuels. Case in point is the Gulf oil crisis of the 1970 's; ${ }^{6}$ - broadly speaking, households are at liberty in utilising fuels when and how they wish subject to availability; ${ }^{8}$ - households derive utility from fuels (especially in meeting their needs - cooking, heating, lighting) which is moderated by possible negative effects (health hazards from burning fuels); ${ }^{10}$ - similar to the SHS scheme, the FBAE does not guarantee egalitarianism since it creates a wide disparity in the quality of energy households can access based on proximity to the grid; ${ }^{12}$ - based on Monyei et al [9], FBAE does not guarantee electricity mobility (which is primarily based on electricity access). However, the FBAE scheme could upgrade rations of distributed fuels for households without any significant need for re-organizing the existing system; ${ }^{14}$ - contributes to emissions in general since primary fuel sources are burnt in households. 